\title{
ВРЕМЕННОЕ СЖАТИЕ СВЕРХКОРОТКИХ ЧАСТОТНО- МОДУЛИРОВАННЫХ СВЕТОВЫХ СИГНАЛОВ СПЕКТРАЛЬНЫМИ ГОЛОГРАММАМИ В СРЕДАХ С ФОТОВЫЖИГАНИЕМ ПРОВАЛОВ
}

A. REBANE. OLILOHIKESTE SAGEDUSMODULEERITUD VALGUSSIGNAALIDE AJALINE KOKKU. SURUMINE JA NENDE AJALISE KUJU TAASTAMINE SPEKTRAALSALKAMISEGA HOLOGRAMMIDE VAHENDUSEL

A. REBANE. TEMPORAL COMPRESSION AND RECOVERY OF ULTRASHORT FREQUENCYMODULATED LIGHT SIGNALS BY PERSISTENT SPECTRAL HOLE-BURNING HOLOGRAMS

\author{
(Представил К. К. Ребане)
}

\section{Введение}

Настоящее сообщение является дальнейшим развитием разрабатываемой в Институте физики АН ЭССР пространственно-временной голографии $\left[{ }^{1-4}\right]$, основанной на использовании уникальных свойств бесфононных линий в спектрах примесных молекул в низкотемпературных матрицах $\left[{ }^{5}\right]$ и метода фотовыжигания спектральных провалов $\left[{ }^{6,7}\right]$ (см. также обзоры $\left.\left[{ }^{8,9}\right]\right)$. В работе продемонстрирована возможность управления сверхкороткими световыми импульсами с помощью голограмм, в том числе восстановления первоначальной формы, утраченной по прохождении импульсом диспергирующей системы (среды).

Предположим, что голоргамма записана таким образом, что ее линейная передаточная характеристика обладает определенной модуляцией по частоте *. При считывании этой голограммы световым импульсом, обладающим частотной модуляцией такого же абсолютного значения, но противоположного знака, на выходе голограммы следует ожидать появления сигнала, частотная модуляция которого оказывается частично или полностью скомпенсированной. Если наличие частотной модуляции у считывающего импульса обуславливает его уширение и расплывание во времени (как это имеет место, например, при передаче широкополосных световых сигналов в диспергирующих средах и оптических волокнах), исключение частотной модуляции спектральной голограммой будет сопровождаться сжатием импульса во времени и устранением его временного расплывания.

В данной работе проведены эксперименты по записи спектральных голограмм с частотно-модулированной передаточной характеристикой и использованию их в качестве согласованных линейных спектральных фильтров, компенсирующих модулящию частоты и осуществляющих сжатие во времени частотно-модулированных пикосекундных световых сигналов.

* С основными принципами пространственно-временной голографии можно ознакомиться по работам $\left[{ }^{3,13}\right]$. 


\section{Описание экспериментальной установки}

Схема экспериментальной установки (рис. 1) состоит из лазерной системы и системы измерения временной структуры пикосекундных сигналов, которые совпадают в основных частях с системой, подробно описанной в $[2,4]$. Длительность импульсов лазера на красителе составляла 10 пс, ширина спектра импульсов - 4,6 нм, частота повторения импульсов - 82 МГц.

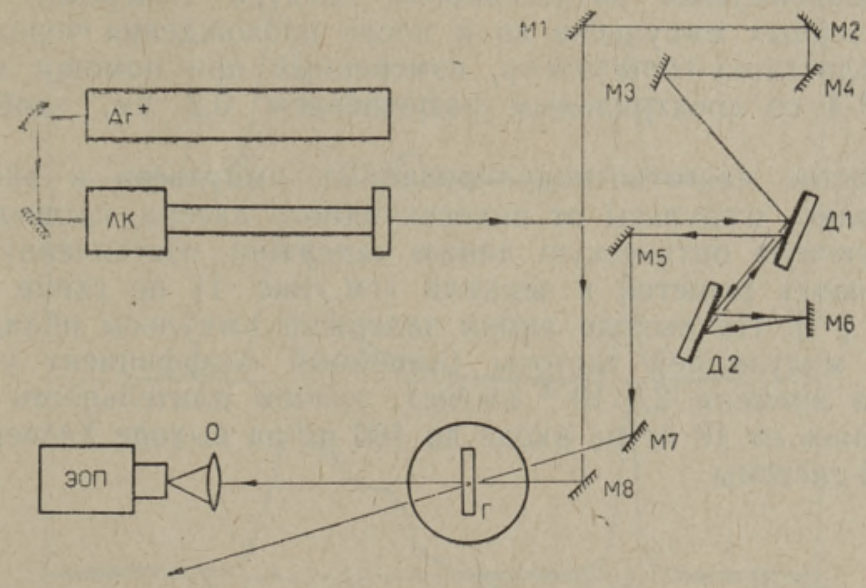

Рис. 1. Схема экспериментальной установки. Д1 и Д2 - дифракционные решетки; M1, M2, M3, M4 - зеркала оптической линии задержки референтных импульсов; M6 - зеркало диспергирующей линий задержки; M5, M7, M8 - направляющие зеркала; Г - голограмма в криостате; О - фокусирующий объектив; ЭОП - электронно-оптический преобразователь; ЛК - пикосекундный лазер на красителе.

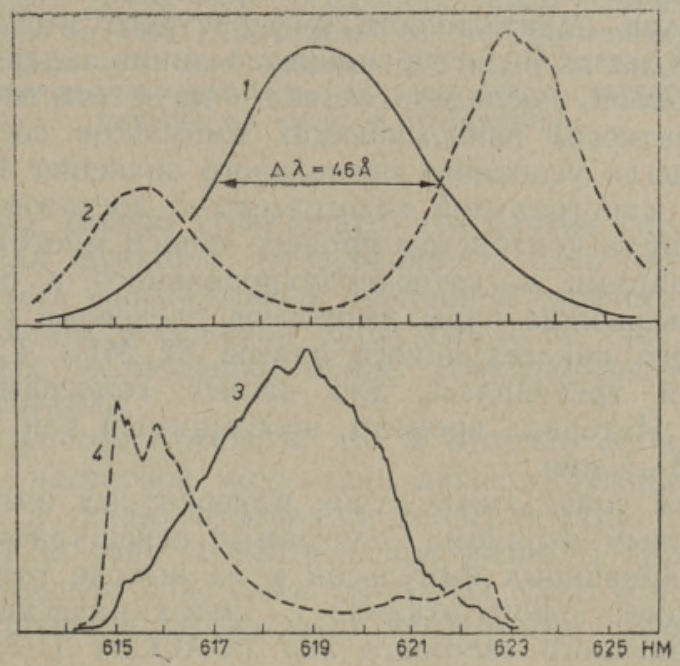

Рис. 2. Спектр референтного (1) и частотно-модулированного (3) импульсов до подачи на регистрирующую среду и соответственно после ее прохождения (2 и 4 ). В спектрах 2 и 4 проявляется поглощение центральной части спектра импульсов не. однородной полосой примесных молекул с максимумом прн 619 нм.

Голограммы записывались на пластинке толщиной 4 мм и гоперечным размером $20 \times 20$ мм. Пластинка-голограмма изготовлялась, как и ранее $[2,4]$, из полистирола с концентрацией примеси (молекул окта- 
этилпорфина) $10^{-3}$ моль/л. Пластинка-голограмма погружалась в иммерсионный гелиевый криостат с оптическими окнами, где она находилась при температуре 1,8 К. Как показали предыдущие эксперименты $\left[{ }^{2,4}\right]$, максимальная длительность сигналов, которые могли записываться на спектральной голограмме в данных экспериментальных условиях, составляла величину порядка 1 нс.

Максимум рабочей неоднородно-уширенной полосы поглощения молекул октаэтилпорфина находился при длине волны 619 нм и совпадал с максимумом интенсивности спектра лазерных импульсов. Спектр лазерных импульсов до и после прохождения через регистрирующую пластинку-голограмму, измеренный при помощи монохроматора МДР-4 со спектральным разрешением 0,2 нм, изображен на рис. 2 .

В качестве частотно-модулированных импульсов в эксперименте использовались импульсы от пикосекундного лазера, прошедшие через дивпергирующую оптическую линию задержки, составленную из двух дифракционных решеток и зеркала (см. рис. 1) по схеме вычитания дисперсии $\left[{ }^{10}\right]$. На выходе линии задержки импульсы обладали отрицательной модуляцией частоты (линейный коэффициент уменьшения частоты во времени $2,5 \cdot 10^{-2}$ нм/пс), причем длительность импульсов увеличивалась от 10 пс на входе до 180 пс на выходе диспергирующей оптической системы.

\section{Результаты и обсуждение}

Для записи голограммы расположенная в криостате регистрирующая пластинка облучалась сперва частотно-модулированным, а затем (с временной задержкой 300 пс) референтным импульсом, который подавался на голограмму под углом $10^{\circ}$ относительно частотно-модулированного импульса. Длительность референтного импульса составляла 10 пс и он исходил из недиспергирующей линии задержки (см. рис. 1). Общая длительность последовательности двух (частотно-модулированного и референтного) записывающих импульсов составляла 600 пс, т. е. не превышала условного предельного значения 1 нс.

Для записи спектральной голограммы с достаточным для ее уверенной регистрации контрастом процесс записи многократно повторяли идентичными парами частотно-модулированного и референтного импульсов. Записывающие пары импульсов следовали с частотой повторения задающего пикосекундного лазера 82 МГц. Суммарная экспозиция, которая требовалась для записи голограммы, составляла 200 мДж $\mathrm{cm}^{-2}$. Интервал времени, необходимый для записи голограммы, составлял $3-5$ мин.

После записи голограммы пучок референтных импульсов преграждали непрозрачным экраном. Голограмма освещалась слабым пучком частотно-модулированных импульсов и на выходе голограммы наблюдался сигнал когерентного отклика - фотохимически аккумулированного стимулированного светового эха (ФАССЭ) $\left[{ }^{1,2}\right]$, дифрагированного голограммой относительно считывающего пучка на $10^{\circ}$. Сигнал ФАССЭ фокусировали объективом на входную щель электронно-оптического преобразователя (ЭОП).

На рис. 3, в приведен результат измерения временной формы сигнала ФАССЭ на выходе голограммы. Широкий импульс с длительностью 200 пс соответствует частотно-модулированному импульсу на входе в голограмму (определенная доля света на входе в голограмму проникала и во входную щель ЭОП'а из-за простого рассеяния). Второй, короткий импульс, изображенный при задержке 600 пс, соответст- 
вует импульсу ФАССЭ на выходе голограммы. Из сравнения этих пмпульсов следует, что в результате пропускания через голограмму длительность частотно-модулированного импульса укорачивалась по крайней мере в шесть раз, т. е. имело место сжатие импульса от первоначальной длительности 180 пс на входе до значения 30 пс на выходе голограммы.

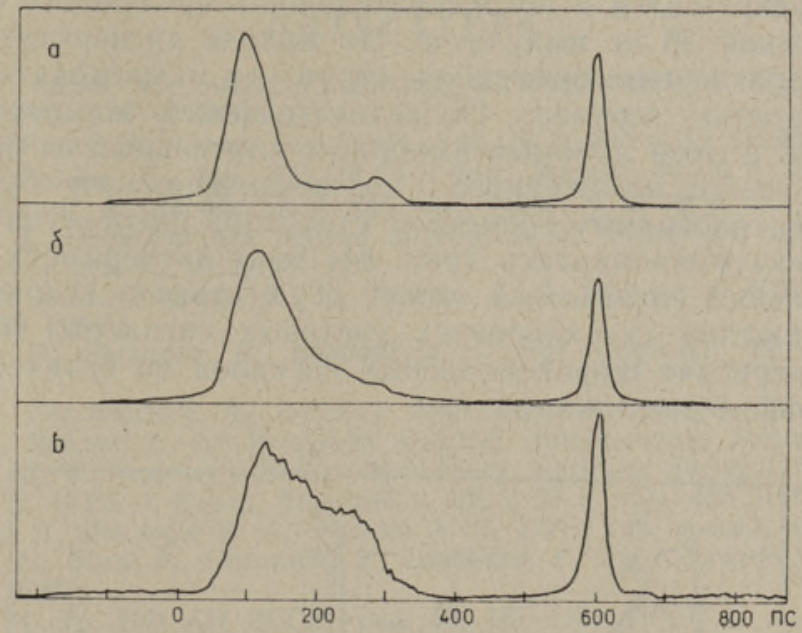

Рис. 3. $a$ - временная форма частотно-модулированного (импульс слева) и референтного импульсов по прохождении через регистрирующую пластинку до записи голограммы. «Провал» в центральной части временной огибающей частотно-модулированного импульса обуславливался поглощением спектральных компонентов с длиной волны в области максимума полосы поглощения регистрирующей среды при 619 нм; б - временная форма этих же импульсов после записывающей экспозиции голограммы. «Провал» частично сглаживается за счет просветления регистрирующей среды; в- короткий импульс при задержке 600 пс - сигнал ФАССЭ на выходе голограммы. Широкий импульс при меньшей задержке - частотно-модулированный импульс на входе в голограмму.

Таким образом, можно утверждать, что данная спектральная голограмма выполняла функцию согласованного спектрального фильтра, восстанавливающего неискаженный временной профиль пикосекундного импульса. Устранение искажений происходило за счет восстановления исходных фазовых соотношений между спектральными компонентами сверхкороткого сигнала.

При этом интересно отметить, что в отличие от известных способов компенсации частотной модуляции диспергирующими оптическими элементами $\left[{ }^{11}\right]$, а также объемными голограммами $\left[{ }^{12}\right]$, где искажения устраняются за счет геометрической разницы длины хода лучей, в данном эксперименте пластинка толщиной всего в несколько миллиметров компенсировала эффективно оптическую разность хода порядка $10 \mathrm{~cm}$.

Это обстоятельство можно осмыслить, если принять во внимание, что спектрально селективная среда голограммы обладает т. н. фазовой памятью (см. напр., $\left.\left[{ }^{13}\right]\right)$, длительность которой эквивалентна максимальной длительности записываемых и воспроизводимых с голограммы сигналов. Таким образом, спектральная голограмма независимо от ма, лости своих геометрических размеров может когерентно преобразовывать и сжимать во времени сигналы, длительность которых не превышает времени «фазовой памяти», что в данных экспернментальных условиях составляло, как уже отмечалось, порядка 1 нс, Легко убе- 
дится, что при использовании обычных методов для этого требуются оптические элементы с длиной хода лучей по крайней мере 30 см.

Далее, эта же голограмма была использөвана для сжатия уже не одиночного импульса, а целой последовательности импульсов сложной временной формы. Для этого в оптический путь лазерного луча до входа в диспергирующую линию задержки вставляли эталон ФабриПеро, на выходе которого каждый одиночный импульс от лазера на красителе превращался в последовательность следующих один за другим с задержкой 36 пс импульсов. На выходе диспергирующей линии задержки характерная временная структура последовательности импульсов полностью терялась. Последовательность коротких импульсов расплывалась в один длинный импульс с длительностью 300 пс. После пропускания этого искаженного до неузнаваемости сигнала через спектральную голограмму временная структура пикосекундного сигнала полностью восстанавливалась (рис. 4). Этот эксперимент показывает, что спектральная голограмма может осуществлять компенсацию временных искажений сверхкоротких световых сигналов, что особенно важно при передаче широкополосных сигналов по оптическим линиям связи на большие расстояния.

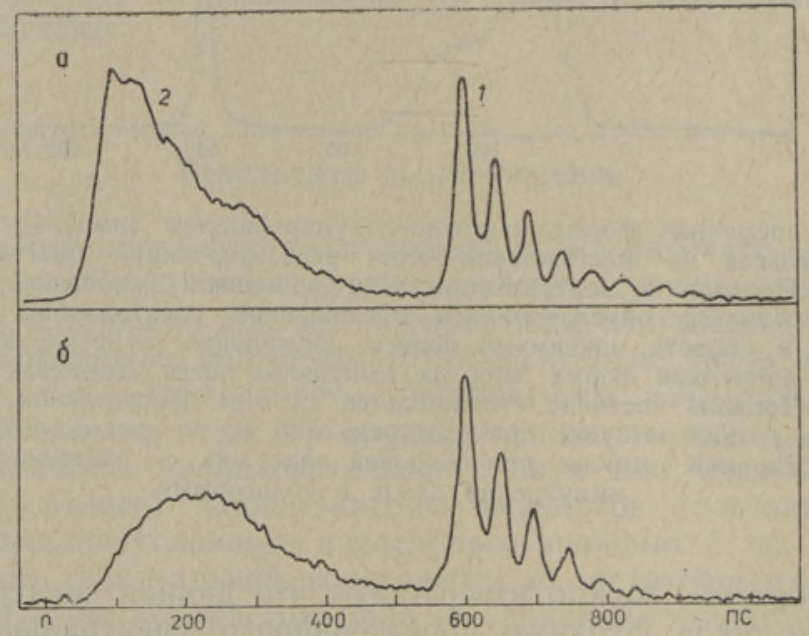

Рнс. 4. $a-$ пикосекундный световой сигнал в виде последовательности коротких импульсов (1) и этот же сигнал после прохождения через диспергирующую линию задержки (2); б - восстановление первоначальной формы пикосекундного сигнала на выходе спектральной голограммы. Широкий импульс при малых задержках - искаженный сигнал на входе в голограмму. Последовательность импульсов при задержке 600 пс - выходной сигнал ФАССЭ.

В заключение отметим, что спектральные голограммы-фильтры на основе сред с фотовыжиганием спектральных провалов могут, в принципе, обладать самыми разнообразными передаточными характеристиками, согласованными с практически любыми линейными амплитудными и фазовыми искажениями сверхкоротких световых сигналов. Ограничивающими факторами являются характеристики собственно ФСП-сред, максимальная рабочая спектральная ширина фильтра, эффективность образования сигнала ФАССЭ и т. п. $\left[{ }^{13}\right]$. В остальном спектральные голограммы можно считать устройствами высокой степени адаптивности, конкретные передаточные характеристики которых можно заранее задавать путем спектрально селективного трансформирования показателей поглощения и преломления рабочей среды или даже быстро их изменять в самом процессе использования фильтров. 
Автор выражает искреннюю благодарность К. К. Ребане и П. Саари за поддержку и обсуждение данной работы, Р. Каарли за обсуждение и содействие при проведении экспериментов, М. Рятсеп за усовершенствование лазерной установки и И. Ренге за изготовление образцов регистрирующей среды.

\section{ЛИТЕРАТУРА}

1. Rebane, A., Kaarli, R., Saari, P., Anijalg, A., Timpmann, K. Opt. Commun., 47, № 3, 173-176 (1983),

2. Rebane, A., Kaarli, R. Chem. Phys, Lett., 101, № 3, 317-319 (1983).

3. Саари П., Ребане А. Изв. АН ЭССР. Физ. Матем., 33, № 3, 322-332 (1984).

4. Saari, P., Kaarli, R., Rebane, A. J. Opt. Soc. Amer. B, 3, № 4, 527-533.

5. Ребане K. K. Элементарная теория колебательной структуры примесных спектров кристаллов. М., «Наука», 1968.

6. Гороховский А. А., Каарли Р. К., Ребане Л. А. Письма в ЖЭТФ, 20, вып. 7, $474-479$ (1974).

7. Kharlamov, B., Personov, R., Bykovskaja, L. Opt. Commun., 12, № 2, 191-194 (1974).

8. Rebane, L., Gorokhovskii, A., Kikas, J. Appl. Phys. B, 29, 235-250 (1982).

9. Rebane, K., Rebane, L. In: Persistent Spectral Hole-Burning: Science and Applications (ed. W. Moerner). Berlin-Heidelberg, Springer Verlag, 1988.

10. Treacy, E. B. IEEE J. Quant. Electronics, QE-5, № 9, 454-458 (1969).

11. Ахманов С. А., Выслоух В. А., Чиркин А. С. УФН, 149, вып. 3, 449-509 (1986),

12. Roblin, M. L., Gires, F., Grousson, R., Lavallard, P. Opt. Commun., 62, № 3, 209214 (1987).

13. Саари П. М. Тр. ИФ АН ЭССР, вып. 59, 157-184 (1987).

Ннститут физики

Академии наук Эстонской ССР
Поступила в редакцию 28/III 1988 